University of Wollongong

Research Online

Faculty of Engineering and Information

Faculty of Engineering and Information

Sciences - Papers: Part A

Sciences

$1-1-2016$

\title{
Experimental study on FRP tube reinforced concrete columns under different loading conditions
}

Weiqiang Wang

University of Wollongong, ww674@uowmail.edu.au

M Neaz Sheikh

University of Wollongong, msheikh@uow.edu.au

Muhammad N. S Hadi

University of Wollongong, mhadi@uow.edu.au

Follow this and additional works at: https://ro.uow.edu.au/eispapers

Part of the Engineering Commons, and the Science and Technology Studies Commons

Research Online is the open access institutional repository for the University of Wollongong. For further information contact the UOW Library: research-pubs@uow.edu.au 


\title{
Experimental study on FRP tube reinforced concrete columns under different loading conditions
}

\author{
Abstract \\ The behavior of fiber-reinforced polymer (FRP) tube reinforced concrete (FTRC) columns under different \\ loading conditions was investigated in this study. Four groups of 16 specimens were cast and tested. \\ Specimens in the first group (the reference group) were re- inforced with longitudinal steel bars and steel \\ helices (Group REF). Specimens in the second group were reinforced with intact glass FRP tubes (Group \\ IT). Specimens in the third group were also reinforced with intact glass FRP tubes. In addition, polymer \\ grid was embedded into the concrete cover to reduce the cover spalling (Group ITG). Specimens in the \\ fourth group were reinforced with perforated glass FRP tubes (Group PT). One specimen from each group \\ was tested under concentric loading, one under 25-mm eccentric loading, one under 50-mm eccentric \\ loading, and one under four-point loading. Results from the experimental study show that FRP tubes \\ significantly increase the load-carrying capacity and ductility of FTRC specimens. Group ITG specimens \\ performed better than the other groups of specimens. Experimental and analytical interaction ( $\mathrm{P}-\mathrm{M})$ \\ diagrams also show the enhanced performance of FTRC specimens.
}

\section{Keywords}

different, loading, experimental, conditions, study, frp, tube, reinforced, concrete, columns, under

\section{Disciplines}

Engineering | Science and Technology Studies

\section{Publication Details}

Wang, W., Sheikh, M. Neaz. \& Hadi, M. N. S. (2016). Experimental study on FRP tube reinforced concrete columns under different loading conditions. Journal of Composites for Construction, 20 (5),

04016034-1-04016034-11. 


\title{
Experimental Study on FRP Tube Reinforced Concrete (FTRC) Columns under Different Loading Conditions
}

\author{
Weiqiang Wang ${ }^{1}$; M. Neaz Sheikh ${ }^{2}$; and Muhammad N.S. Hadi, F.ASCE ${ }^{3}$
}

Abstract: The behavior of fiber-reinforced polymer (FRP) tube reinforced concrete (FTRC)

columns under different loading conditions was investigated in this study. Four groups of 16 specimens were cast and tested. Specimens in the first group (reference group) were reinforced with longitudinal steel bars and steel helices (Group REF). Specimens in the second group were reinforced with intact glass FRP tubes (Group IT). Specimens in the third group were also reinforced with intact glass FRP tubes. In addition, polymer grid was embedded into the concrete cover to reduce the cover spalling (Group ITG). Specimens in the fourth group were reinforced with perforated glass FRP tubes (Group PT). From each group, one specimen was tested under concentric loading, one specimen under $25 \mathrm{~mm}$ eccentric loading, one specimen under $50 \mathrm{~mm}$ eccentric loading, and one specimen under four-point loading. Results from the experimental study show that FRP tubes significantly increase the load carrying capacity and ductility of FTRC specimens. Group ITG specimens performed better than the other groups of specimens. Experimental and analytical interaction $(P-M)$ diagrams also show the enhanced performance of FTRC specimens.

CE Database subject headings: FRP tube; Columns; Eccentric loading; Four-point loading; Interaction diagram.

\footnotetext{
${ }^{1}$ Ph.D. Candidate, School of Civil, Mining and Environmental Engineering, University of Wollongong, Wollongong NSW 2522 Australia. E-mail: ww674@uowmail.edu.au

${ }^{2}$ Senior lecturer, School of Civil, Mining and Environmental Engineering, University of Wollongong, Wollongong NSW 2522 Australia. E-mail: msheikh@uow.edu.au

${ }^{3}$ Associate Professor, School of Civil, Mining and Environmental Engineering, University of Wollongong, Wollongong NSW 2522, Australia (corresponding author).E-mail: mhadi@uow.edu.au
} 
Introduction

Concrete-filled FRP tubes (CFFTs) has been widely investigated in recent years. In CFFTs, the FRP tube acts as a stay-in-place structural formwork for the concrete and provides lateral confinement to concrete under compression. Moreover, the concrete can increase the stiffness of the members and prevent the FRP tube from local buckling. Many studies revealed that significant increases in the strength and ductility can be observed for CFFTs subject to compressive loadings, which makes CFFTs a promising alternative to steel reinforced concrete (RC) columns (Mirmiran et al. 1998; Fam and Rizkalla 2001, 2002; Fam et al. 2003; Ozbakkaloglu 2013).

Recently, a new type of composite column named FRP tube reinforced concrete (FTRC) columns was proposed (Hadi et al. 2015). This composite column consists of an inner CFFTs and a concrete cover. In FTRC columns, the adverse influences of freeze-thaw cycles and ultraviolet radiation on the FRP tube are expected to be avoided by the concrete cover (Cromwell et al. 2011; Green et al. 2006; Karbhari et al. 2003), and a higher temperature resistance can be obtained because the concrete cover can prevent the FRP tube from exposure of high temperature (Cree et al. 2012; Jau and Huang 2008; Ji et al. 2008; Yu and Kodur 2013). Moreover, the spalling of concrete cover can be used as a suitable indication before the brittle failure of FTRC columns. Previous studies showed that FTRC columns can obtain a considerable strength and ductility capacity under concentric loading (Hadi et al. 2015).

FTRC columns are susceptible to premature spalling of concrete cover because the concrete core and concrete cover is separated by the FRP tube. Perforated tubes have been used to integrate the concrete core and concrete cover (Hadi et al. 2015; Sezen and Shamsai 2008; Rethnasamy et al. 2013). However, the perforation may lead to performance degradation of FTRC columns. In this study, the polymer grid has been used to prevent the premature 
spalling of concrete cover (Hadi and Zhao 2011; Heo et al. 2011; Park et al. 2015). The construction process of FTRC columns in real application can be similar to that of steel RC columns in which the concrete cover is confined with grid mesh (Heo et al. 2011). Before the construction, the FRP tubes and polymer grid are manufactured with required sizes, and then the polymer grid is prefabricated into tubular shape in order to provide confinement to concrete cover. After the FRP tube is properly assembled on site, the tubular polymer grid can be assembled outside the FRP tube. In order to maintain the distance from the tubular polymer grid to the FRP tube, commercial available spacers can be placed onto the tubular polymer grid (Heo et al. 2011). Finally, the outside formwork is installed and the concrete can be poured.

Even though the behavior of FTRC columns under concentric loading has been investigated (Hadi et al. 2015), the behavior of FTRC columns under eccentric loading and flexural loading has not been extensively investigated yet. It was revealed that the confinement of FRP to concrete is less effective for columns under eccentric loading and flexural loading (Fam et al. 2003; Wu and Jiang 2013; Yu et al. 2010). Moreover, the size of FTRC columns in Hadi et al. (2015) was rather small (150 $\mathrm{mm}$ in diameter and $300 \mathrm{~mm}$ in height). In order to investigate the possibility of using FTRC columns in real application, FTRC columns with larger size should be tested. Therefore, an experimental program was conducted in this study to investigate the behavior of FTRC members (240 $\mathrm{mm}$ in diameter and $800 \mathrm{~mm}$ in height) under different loading conditions. Furthermore, experimental and analytical interaction $(P$ $M$ ) diagrams were constructed to investigate the axial load and bending moment capacity of FTRC members. 


\section{Experimental Program}

79

80

\section{Design of Experiment}

A total of 16 specimens with a length of $800 \mathrm{~mm}$ and a diameter of $240 \mathrm{~mm}$ were cast and tested under concentric, eccentric $(25 \mathrm{~mm}$ and $50 \mathrm{~mm})$, and four-point loadings. The specimens were divided into four groups with four specimens in each group. The first group (Group REF) was a reference group in which the four specimens were reinforced with steel helices and longitudinal steel bars (Fig. 1(a), (d)). The reinforcement consisted of 6N12 bars (12 mm deformed bars with a nominal tensile strength of $500 \mathrm{MPa}$ ) as longitudinal reinforcement and R10 bars (10 mm plain bars with a nominal tensile strength of $250 \mathrm{MPa})$ as transverse reinforcement in the form of helix with a pitch of $50 \mathrm{~mm}$. The reinforcement ratio of specimens in Group REF was $1.5 \%$. The second group (Group IT) contained four FRP tube reinforced concrete (FTRC) specimens which were reinforced with intact glass fiber-reinforced polymer (GFRP) tubes (Fig. 1(b), (e)). The GFRP tubes had an inner diameter of $167 \mathrm{~mm}$ with a thickness of $8 \mathrm{~mm}$. The third group (Group ITG) contained four FTRC specimens reinforced with intact GFRP tubes. Moreover, two layers of polymer grid were embedded into the concrete cover to reduce the cover spalling (Fig. 1 (c), (f)). The fourth group (Group PT) contained four FTRC specimens which were reinforced with perforated GFRP tubes (Fig. 1 (b), (g)). The reinforcement ratio of FTRC specimens in Groups IT, ITG, and PT was 9.7\%. For the specimens in each group, the first specimen was subjected to concentric loading, while the second and the third specimens were subjected to eccentric loadings with 25 and $50 \mathrm{~mm}$ eccentricities, respectively. The fourth specimen was tested as a beam under four-point loading to evaluate the flexural behavior. Table 1 shows the test matrix of the experiment. The notation of the specimens consists of two parts: the first part is REF, IT, ITG, or PT, which indicates the groups of the specimens. The second part is $0,25,50$, or $\mathrm{F}$, which indicates the loading conditions ( 0 indicates concentric loading; 25 
indicates eccentric loading with $25 \mathrm{~mm}$ eccentricity; 50 indicates eccentric loading with 50 mm eccentricity; and $\mathrm{F}$ indicates four-point loading).

\section{Specimen Preparation}

The GFRP tubes were manufactured by Exel Composites Australia (2015) based in Boronia, Victoria, Australia. The GFRP tubes were made from vinyl ester resin systems with E-glass fiber. The mechanical properties of GFRP tubes provided by the manufacturers are listed in Table 2. For the construction of perforated GFRP tubes, exact locations of the holes were marked before the perforation. Afterwards, a drill press machine with a circular drill bit was used to perforate the GFRP tubes. Three columns of holes were drilled onto each GFRP tube. The holes were symmetrically distributed along the tube circumference with a clear lateral spacing of $165 \mathrm{~mm} .15 \mathrm{~mm}$ diameter circular holes were drilled. The clear vertical hole spacing was $60 \mathrm{~mm}$.

The polymer grid was rectangular in shape (36 $\mathrm{mm}$ spacing in the longitudinal direction and $24 \mathrm{~mm}$ spacing in the transverse direction) and was manufactured from high modulus polyester fibers by Maccaferri Australia Pty Ltd. (2015). In order to provide transverse confinement to the concrete cover, the polymer grid was formed into tubular shapes and held with plastic ties. The polymer grid was overlapped at an approximate length of $100 \mathrm{~mm}$ to ensure that the polymer grid would not be loosened or slid and to provide uniform confinement to the concrete cover.

The molds for casting the specimens were made of PVC pipe with an inner diameter of 240 $\mathrm{mm}$ and a height of $800 \mathrm{~mm}$. All the molds were aligned vertically by a formwork made from timber. The concrete was supplied by a local concrete provider, and the nominal compressive strength was $32 \mathrm{MPa}$. Before pouring the concrete in the molds, the steel reinforcement 
cages, GFRP tubes, and tubular polymer grids were placed into the molds. After casting, all the specimens were covered with wet burlap on top to prevent moisture loss. All the specimens were kept wet during the weekdays until the test date.

\section{Preliminary Tests}

Compressive tests of concrete cylinders on 28 days showed that the average compressive strength of the concrete was $35 \mathrm{MPa}$. The tensile properties of N12 deformed bars and R10 plain bars were tested in accordance with AS 1391 (2007) using Instron 8033 testing machine. Based on the average results of tensile tests, the yield strength of N12 deformed bars was $440 \mathrm{MPa}$, and the yield strength of R10 plain bars was $400 \mathrm{MPa}$.

Tensile properties of the polymer grid were determined by testing polymer grid strand using Instron 8033 machine. Each end of the polymer grid strand was embedded in steel clamps. The two steel plates were then tightened towards each other in order to fix the polymer grid. The total length of the polymer grid strand was $158 \mathrm{~mm}$ with a free length of $102 \mathrm{~mm}$. The displacement controlled test was carried out at a rate of $3 \mathrm{~mm} / \mathrm{min}$. A linear elastic behavior was observed, and the average tensile strength of the polymer grid was $484 \mathrm{MPa}$ with an elastic modulus of $5 \mathrm{GPa}$.

The GFRP tubes were tested under compression in accordance with GB/T 5350 (2005). Before testing, the tube was placed onto the bottom loading plate to check whether there was any misalignment between the tube end and the bottom loading plate (Wang et al. 2015b). If a slight misalignment was observed, the tube end was slightly smoothed using a belt sander until the misalignment was removed. The test was conducted at a rate of $0.3 \mathrm{~mm} / \mathrm{min}$. The average axial compressive strength of GFRP tube was $416 \mathrm{MPa}$ with a corresponding axial strain of 0.0145 . Due to the limitations of the experimental setup, the hoop tensile properties 
of the GFRP tubes cannot be experimentally obtained. Therefore, the hoop tensile properties of the GFRP tubes provided by the manufacturers were used for further analysis.

\section{Instrumentation and Test Procedure}

The Denison 5,000 kN compression testing machine was used for testing all the specimens. For concentrically and eccentrically loaded column specimens, the specimen ends were capped with high-strength plaster to ensure uniform load distribution. In order to apply eccentric loading onto the column specimens, a set of loading heads were used (Fig. 2). Axial deformations of the column specimens were measured using two Linear Variable Differential Transducers (LVDTs), which were mounted at the opposite corners between the bottom loading plate and the top steel plate of the Denison testing machine. In order to measure the lateral deflections for the eccentrically loaded column specimens, a laser triangulation was set up at mid-height of the column specimen. For the flexural test, a four-point loading system was manufactured, as shown in Fig. 3. The four-point loading system was composed of a top rig and a bottom rig. The bottom rig was placed diagonally on the bottom loading plate of the Denison testing machine, and then the beam specimen was placed on the bottom rig. Afterwards, the top rig was placed on the beam specimen. The top plate of the Denison testing machine was adjusted to the top rig to apply load. A hole was drilled onto the middle of bottom rig and a laser triangulation was located underneath the bottom rig for the recording of mid-span deflection of the beam specimens. All the tests were conducted as deflection controlled at a rate of $0.3 \mathrm{~mm} / \mathrm{min}$.

\section{Experimental Results and Discussions}

\section{Behavior of Specimens under Concentric Load}


The failure modes of concentrically loaded specimens are shown in Fig. 4. Specimen REF-0 failed gradually due to cover spalling and the buckling of longitudinal bars. Specimens IT-0 and ITG-0 failed suddenly due to the hoop rupture of GFRP tubes accompanied by a loud noise, while Specimen PT-0 failed due to the premature failure at the top end of the specimen. For Specimens REF-0 and IT-0, most of the concrete cover spalled off at the time of failure, while the spalling of concrete cover was effectively controlled by the polymer grid for Specimen ITG-0 (Fig. 4 (c)).

The yield load, ultimate load and the corresponding axial deformations of the specimens are shown in Table 3. In this study, the yield load was defined as the limit of elastic behavior of specimens (Pessiki and Pieroni 1997): A best-fit line to the linear portion of the loaddeformation curve was implemented. This line was then extrapolated to intersect with the maximum load before cover spalling. The load corresponding to this intersection was the yield load. Fig. 5 shows the axial load-axial deformation behavior of Specimens REF-0, IT-0, ITG-0, and PT-0. Similar behavior has been observed before the yielding of Specimens REF0, IT-0, and ITG-0. After the initial ascending branch, all specimens experienced load reductions due to the spalling of concrete cover. A continuous decrease of axial load was observed for Specimen REF-0. While for Specimens IT-0 and ITG-0, the axial load began to increase again since the confinement provided by the GFPR tube to the concrete core was activated as well as the increased axial load carried by the GFRP tube. Even though higher ultimate loads can be observed for Specimens IT-0 and ITG-0, the axial deformations at ultimate loads were significantly less than that of Specimen REF-0. This phenomenon was attributed to the low hoop tensile properties of GFRP tubes. Therefore, Specimens IT-0 and ITG-0 failed due to the hoop tensile rupture of GFRP tubes before the axial compressive strength of GFRP tubes can be fully utilized. Similar behavior was also observed by Fam and Rizkalla (2001) and Bank (2013). Moreover, by comparing the axial load-axial deformation 

in load carrying capacity or deformation capacity due to the embedment of polymer grid into the concrete cover of Specimen ITG-0. This is because the confinement provided by the polymer grid to the concrete cover was weak due to its large openings as well as its lower tensile strength and tensile elastic modulus (Wang et al. 2015a).

The confinement ratio (the ratio between the lateral confining pressure $f_{l}$ and the unconfined concrete strength $f_{c o}^{\prime}$ ) was used to investigate the strength improvement of concrete. For

Group REF specimens, the confinement ratio was calculated (Mander et al. 1988):

$$
\frac{f_{l}}{f_{c o}^{\prime}}=\frac{2 k_{e} A_{t s} f_{y h}}{d_{s} s f_{c o}^{\prime}}
$$

where $k_{e}=\left(1-s^{\prime} / 2 d_{s}\right) /\left(1-\rho_{c c}\right)$ is the confinement effectiveness coefficient, $A_{t s}$ is the area of transverse bars, $f_{y h}$ is the yield strength of the transverse bars, $s$ is the center to center spacing of neighboring helices, $s^{\prime}$ is the clear spacing between neighboring helices, $d_{s}$ is the diameter of steel helices between bar centers, and $\rho_{c c}$ is the ratio of total area of longitudinal reinforcement to the area of concrete core.

For Group IT and ITG specimens, the confinement ratio was calculated (Teng et al. 2009):

$$
\frac{f_{l}}{f_{c o}^{\prime}}=\frac{2 t f_{t}}{D_{c o r e} f_{c o}^{\prime}}
$$

214 where $t$ is the tube thickness, $f_{t}$ is the hoop tensile strength of FRP tube, and $D_{\text {core }}$ is the diameter of concrete core.

The confinement ratio for specimens in Group REF was 0.16 , and the confinement ratio for specimens in Groups IT and ITG was 0.137. For specimens in Group PT, the confinement ratio cannot be obtained because the confinement provided by the perforated FRP tube was 
non-uniform and was difficult to be determined. Even though the confinement ratios were close to each other, the ultimate load of Specimen REF-0 was significantly less than those of Specimens IT-0 and ITG-0. This phenomenon was mainly attributed to that the load carried by FRP tube was significantly higher than the load carried by the longitudinal bars at ultimate load. According to the readings from strain gauges, Specimens IT-0 and ITG-0 failed at longitudinal compressive strains of 0.00645 and 0.00659 , respectively. Therefore, the axial load carried by the FRP tube was calculated to be $808.5 \mathrm{kN}$ and $825.0 \mathrm{kN}$, respectively ( $P_{\text {tube }}=E_{a, f} \varepsilon_{a, f} A_{\text {tube }}$, where $E_{a, f}$ is the longitudinal compressive elastic modulus of FRP tube, $\varepsilon_{a, f}$ is the longitudinal compressive strain of FRP tube at failure, and $A_{\text {tube }}$ is the cross section area of FRP tube). However, the maximum axial load carried by longitudinal bars was calculated to be $298.6 \mathrm{kN}$ ( $P_{\text {steel }}=f_{y l} A_{l s}$, where $f_{y l}$ and $A_{l s}$ are the yield strength and the total area of longitudinal bars, respectively), and this load would further decrease because of the buckling of longitudinal bars after the spalling of concrete cover. Therefore, the ultimate load of REF-0 was significantly lower than those of Specimens IT-0 and ITG-0 even though the confinement ratios were similar.

For Specimens IT-0 and ITG-0, the increased load carried by the concrete core due to the FRP confinement was calculated $\left(P_{u}-P_{\text {tube }}-f_{c o}^{\prime} A_{\text {core }}\right.$, where $P_{u}$ is the ultimate load of FTRC columns, and $A_{\text {core }}$ is the area of concrete core). The increased loads carried by concrete core were $285.0 \mathrm{kN}$ and $267.6 \mathrm{kN}$ for Specimens IT-0 and ITG-0, respectively. Therefore, it can be seen that for Specimens IT-0 and ITG-0, the load contribution from the longitudinal compressive properties of FRP tube was more significant than the gain from the confinement of concrete. 
244 The failure modes of Specimens REF-25, IT-25, ITG-25, and PT-25 are shown in Fig. 6. 245 Specimen REF-25 failed due to the crushing of concrete and local buckling of longitudinal bars in the compression region. Specimens IT-25, ITG-25, and PT-25 failed due to the rupture of GFRP tubes in the compression region with a loud noise, and no rupture was observed onto the GFRP tubes in the tension region.

The behavior of Specimens REF-25, IT-25, ITG-25, and PT-25 under eccentric loading is shown in Fig. 7. For Specimen REF-25, the axial load decreased continuously after the initial ascending branch. While for FTRC specimens, the axial loads began to increase again after the initial load reductions, which was mainly attributed to that the axial load carried by GFRP tube was continuously increased. The axial stiffness of GFRP tube $k_{f}$ was calculated to be 173.6 GPa $\cdot \mathrm{mm}\left(k_{f}=E_{a, f} A_{\text {tube }} / L\right.$, where $E_{a, f}, A_{\text {tube }}$, and $L$ are the longitudinal compressive elastic modulus, cross section area, and length of FRP tube, respectively), and the axial stiffness of longitudinal bars $k_{s}$ can be calculated to be $178.6 \mathrm{GPa} \cdot \mathrm{mm}\left(k_{s}=E_{s} A_{l s} / L\right.$, where $E_{s}, A_{l s}$, and $L$ are the elastic modulus, total cross section area, and length of longitudinal bars, respectively). Even though the axial stiffness of FRP tube and longitudinal bars were close to each other, the longitudinal bars began to buckle after the spalling of concrete cover. Hence, the load carried by longitudinal bars was decreased. However, no buckling was observed for FRP tube, and the load carried by the FRP tube was continuously increased with the increased of axial deformation. Therefore, higher ultimate loads can be observed for FTRC specimens. Specimen ITG-25 obtained the highest ultimate axial load, followed by Specimens IT-25, PT-25, and REF-25. The performance difference between Specimens ITG25 and IT-25 was not significant, which indicates that the polymer grid was not effective in increasing the load carrying capacity and deformation capacity of the specimens. For 
Specimen PT-25, the ultimate load was significantly lower than those of Specimens ITG-25 and IT-25 because the perforation caused strength reduction of the GFRP tube. Table 3 summarizes the test results of Specimens REF-25, IT-25, ITG-25, and PT-25. The yield loads of Specimens IT-25, ITG-25, and PT-25 were slightly higher than that of Specimen REF-25. The increases of the ultimate loads for Specimens IT-25, ITG-25, and PT-25 compared to the ultimate load of REF-25 were $49.5 \%, 58.0 \%$, and $42.0 \%$, respectively.

The behavior of Specimens REF-50, IT-50, ITG-50, and PT-50 under eccentric loading is shown in Fig. 8. Similar failure modes can be observed between specimens under $50 \mathrm{~mm}$ eccentric loading and specimens under $25 \mathrm{~mm}$ eccentric loading. The test results are summarized in Table 3. The increases of the ultimate loads of Specimens IT-50, ITG-50, and PT-50 compared to that of REF-50 were $49.1 \%, 50.3 \%$, and $31.5 \%$, respectively. The ultimate load of Specimen PT-50 was significantly less than that of Specimens IT-50 and ITG-50, which was due to the influence of perforation onto the GFRP tube.

Moreover, it can be observed from Table 3 that for eccentrically loaded FTRC specimens, the axial deformations at ultimate loads were higher than the corresponding axial deformations for concentrically loaded FTRC specimens, and the axial deformations at ultimate loads were increased with the increase of eccentricity. This can be explained by the fact that with the increase of eccentricity, the expansion of concrete core was less due to the existence of strain to the high bending stiffness of FRP tubes ( $E_{a, f} I$, where $E_{a, f}$ is the longitudinal compressive elastic modulus of FRP tube, and $I$ is the area of moment of inertia). In this study, the bending gradient. Therefore, the transverse tensile rupture of GFRP tube may occur with a higher axial strain. Moreover, it is observed that the lateral deflections of eccentrically loaded FTRC specimens were less than those of corresponding axial deformations, which may be attributed stiffness of FRP tube can be calculated by $\pi D^{4}\left(1-\alpha^{4}\right) E_{a, f} / 64$, where $\alpha$ is the ratio between 
the inner diameter and outer diameter of FRP tube, and $D$ is the outer diameter of FRP tube. The bending stiffness of FRP tube was calculated to be $495469 \mathrm{~Pa} \cdot \mathrm{m}^{4}$. Therefore, the FRP tubes can be effective in resisting the lateral deflections of eccentrically loaded FTRC specimens.

\section{Flexural Behavior}

The failure modes of beam specimens after test are shown in Fig. 9. For Specimens IT-F, ITG-F, and PT-F, the failures were caused by the rupture of the GFRP tubes in the tension sides. Specimen REF-F failed due to the combination of flexural cracks and inclined shear cracks. This observation suggested that FRP tube was more effective in controlling the development of shear cracks (Mandal and Fam 2006). Almost all the concrete cover of Specimens IT-F and PT-F spalled off at the time of failure. Nevertheless, the failure mode of Specimen ITG-F indicates that the polymer grid can be effective in preventing the spalling of concrete cover.

The test results of beam specimens are presented in Table 4. Fig. 10 shows the load-mid-span deflection behavior of the tested specimens under four-point loading. At the initial stage, similar load-mid-span deflection behavior can be observed. Afterwards, load reductions can be observed for all specimens because of the spalling of the concrete cover. After these load reductions, the loads of all tested specimens were fluctuated, which resulted in a redistribution and rearrangement of the forces within the specimens. For Specimen REF-F, a higher load was obtained even after the spalling of the concrete cover. In order to obtain the theoretical bending moment capacity of Specimen REF-F with pure flexural failure, a rectangular stress block method suggested in AS 3600 (2009) was used. The theoretical bending moment capacity was found to be $27.5 \mathrm{kN} \cdot \mathrm{m}$, which was less than the experimental 

Specimen REF-F failed due to the combined effect of flexural cracks and inclined shear cracks. Therefore, direct diagonal compression strut was developed in the concrete through the arching action, which resulted in an increase in the performance of concrete beam (Mohamed and Masmoudi 2010; Pham et al. 2013); and (2) the confinement provided by the steel helix is more effective than that provided by rectangular or square stirrups, which resulted in a higher bending moment capacity (Hadi and Schmidt 2002). For Specimens IT-F and PT-F, the FRP tube ruptured immediately after the spalling of concrete cover (the longitudinal compressive strains of FRP tube at rupture in the extreme compression fiber were 0.0025 and 0.0016 , respectively), which resulted in sudden load reductions of specimens. Therefore, the maximum load $\left(P_{u}\right)$ was the same with the maximum load before cover spalling $\left(P_{y}\right)$, and hence the bending moment $M_{y}$ was equal to $M_{u}$. After these load reductions (from $337 \mathrm{kN}$ to $227 \mathrm{kN}$ for Specimen IT-F and from $311 \mathrm{kN}$ to $266 \mathrm{kN}$ for Specimen PT-F), Specimens IT-F and PT-F could still carry substantial amount of loads with increasing mid-span deflection until failure. For Specimen ITG-F, the FRP tube ruptured at a longitudinal compressive strain of around 0.0045 in the extreme compression fiber. Therefore, Specimen ITG-F could be further loaded to obtain higher load and higher mid-span deflection after the spalling of concrete cover.

\section{Ductility Capacity}

The ductility of steel RC column can be calculated as the ratio of the axial deformation at the $85 \%$ post-ultimate load divided by the axial deformation at the yield load, which can be expressed as: 


$$
\mu=\frac{\delta_{u}}{\delta_{y}}
$$

where $\mu$ is the ductility, $\delta_{u}$ is the axial deformation at the $85 \%$ post-ultimate load, and $\delta_{y}$ is the axial deformation at the yield load.

The above definition of ductility was not applicable for FTRC columns. In this study, the ductility definition suggested by Cui and Sheikh (2010) was adopted to calculate the ductility of FTRC columns. According to Cui and Sheikh (2010), the ultimate load was defined as the load at the failure of FRP, while the same definition of yield load suggested by Pessiki and Pieroni (1997) was adopted.

The ductility of all column specimens is summarized in Table 3. It can be seen that FTRC columns obtained higher ductility than steel RC columns under both concentric and eccentric loadings, and the ductility of FTRC columns increase with the increase of eccentricity. It is noted that for Specimen REF-0, a considerable amount of axial deformation can still be observed after $85 \%$ post-ultimate load. Moreover, when the applied load changes from concentric loading to eccentric loadings of $25 \mathrm{~mm}$ and $50 \mathrm{~mm}$, the decrease of axial loads of Group REF columns was $34.0 \%$ and $53.3 \%$, respectively. The corresponding decreases in axial loads were $21 \%$ and $44 \%$, respectively, for Group IT columns. While for Group ITG columns, the load decreases were $16 \%$ and $44 \%$, respectively. For specimens under eccentric loading, the percentages of load reductions were less for FTRC columns than steel RC columns. Therefore, the FTRC columns are preferred to the steel RC columns especially under eccentric loadings.

\section{Interaction Diagram}


359 Axial load-bending moment $(P-M)$ interaction diagrams were constructed to investigate the 360 axial load and bending moment capacity of the specimens. For eccentrically loaded 361 specimens, the bending moment capacities considering the secondary moment were 362 calculated by Equation (4):

$$
M=P_{u}(e+\delta)
$$

363 where $P_{u}$ indicates ultimate axial load, $e$ indicates loading eccentricity, and $\delta$ indicates lateral deflection at the ultimate load.

For beam specimens, the bending moment capacities were calculated by Equation (5):

$$
M=\frac{P_{u}}{2} \cdot a
$$

where $a$ is length of shear span ( $a=230 \mathrm{~mm}$ ), as shown in Fig. 3 (b).

The experimental interaction diagrams are shown in Fig. 11. The interaction diagrams indicate that FTRC specimens (Groups IT, ITG, and PT) outperformed steel RC specimens in this study. The interaction diagrams of FTRC specimens can be divided into two parts. In the first part, the axial load increased with the increase of bending moment. While in the second part, the axial load increased with the decrease of bending moment. The interaction diagram of steel RC specimens (Group REF) was not as expected since the axial load increased with a continuous decrease of bending moment. This phenomenon was because Specimen REF-F failed due to a combination of flexural cracks and shear cracks (Fig. 9 (a)). The shear cracks resulted in an arch action, which increased the bending moment capacity.

A numerical layer-by-layer approach was used to construct the analytical interaction diagrams of FTRC specimens (Fam et al. 2003; Yazici and Hadi 2009). The cross section of FTRC specimens was divided into finite small horizontal strips, as shown in Fig. 12. In each layer, the area of FRP tube, concrete core, and concrete cover were calculated. With the plain 
section assumption, the strain in each strip was estimated and the axial stress of each component was calculated by the stress-strain models of different components. The calculated stresses are then integrated over the whole cross section area to obtain the resultant

383 force and the resultant moment. In order to get more accurate prediction results, the width of 384 these strips should be small enough. In this study, the width of these small strips was taken as $3851 \mathrm{~mm}$.

A linear elastic stress-strain relationship was adopted in both longitudinal and transverse directions of FRP tubes. Different stress-strain models were adopted for the concrete core and concrete cover of FTRC specimens. It was observed that the confinement effect provided by polymer grid was insignificant. Therefore, the confinement effect of polymer grid was neglected in this analysis. The stress-strain model proposed by Popovics (1973) was adopted to simulate the concrete cover of FTRC specimens:

$$
\sigma_{c}=\frac{f_{c o}^{\prime} x r}{r-1+x^{r}}
$$

392 where

$$
\begin{gathered}
x=\frac{\varepsilon_{c}}{\varepsilon_{c o}} \\
r=\frac{E_{c}}{E_{c}-E_{s e c}} \\
E_{s e c}=\frac{f_{c o}^{\prime}}{\varepsilon_{c o}}
\end{gathered}
$$

where $\sigma_{c}$ and $\varepsilon_{c}$ are axial stress and axial strain of concrete, respectively; $f_{c o}^{\prime}$ is compressive strength of unconfined concrete; and $\varepsilon_{c o}$ is compressive strain of concrete corresponding to $f_{c o}^{\prime} ; E_{c}$ is the elastic modulus of unconfined concrete; and $E_{s e c}$ is the secant modulus of unconfined concrete. 

FTRC specimens subjected to concentric compression, which can be described by the following expressions:

$$
\begin{array}{cc}
\sigma_{c}=E_{c} \varepsilon_{c}-\frac{\left(E_{c}-E_{2}\right)^{2}}{4 f_{c o}^{\prime}} \varepsilon_{c}^{2} \text { for } 0 \leq \varepsilon_{c} \leq \varepsilon_{t} \\
\sigma_{c}=f_{c o}^{\prime}+E_{2} \varepsilon_{c} \quad \text { for } \varepsilon_{t} \leq \varepsilon_{c} \leq \varepsilon_{c u}
\end{array}
$$

400

401

402

403 linear second portion with a smooth transition at $\varepsilon_{t}$ :

$$
\varepsilon_{t}=\frac{2 f_{c o}^{\prime}}{\left(E_{c}-E_{2}\right)}
$$

404 The slope of the linear second portion $E_{2}$ is given by

$$
E_{2}=\frac{f_{c c}^{\prime}-f_{c o}^{\prime}}{\varepsilon_{c u}}
$$

405

where $f_{c c}^{\prime}$ is the compressive strength of confined concrete. The expressions for $f_{c c}^{\prime}$ and $\varepsilon_{c u}$ 406 are:

$$
\begin{gathered}
\frac{f_{c c}^{\prime}}{f_{c o}^{\prime}}=\left\{\begin{array}{cc}
1 & \rho_{K}<0.01 \\
1+3.5\left(\rho_{K}-0.01\right) \rho_{\varepsilon} & \rho_{K} \geq 0.01
\end{array}\right. \\
\frac{\varepsilon_{c u}}{\varepsilon_{c o}}=1.75+6.5 \rho_{K}^{0.8} \rho_{\varepsilon}^{1.45}
\end{gathered}
$$

407 where $\rho_{K}=2 E_{f r p} t /\left(E_{\text {sec }} D_{\text {core }}\right)$ is the confinement stiffness ratio; $\rho_{\varepsilon}=\varepsilon_{h, \text { rup }} / \varepsilon_{c o}$ is the strain 408 ratio. $E_{f r p}$ is the elastic modulus of FRP tube in the hoop direction, $t$ is the thickness of FRP 409 tube, $\varepsilon_{h, \text { rup }}$ is the hoop rupture strain of FRP tube, and $D_{\text {core }}$ is the diameter of the confined 
Moreover, in order to consider the reduced effectiveness of FRP confinement for concrete

412

413

414 core subjected to eccentric loading and flexural loading, a variable confinement model was adopted to describe the stress-strain relationship of concrete core under eccentric loading and flexural loading (China Planning Press 2010; Yu et al. 2010). This model is an extension of Teng et al. (2009) model. The only difference is the value of the slope of the second linear portion of the concrete stress-strain curve. For concrete under eccentric loading and flexural loading, the slope of the second linear portion of the stress-strain curve was calculated as:

$$
E_{2 e c}=E_{2} \frac{D_{o}}{D_{o}+e}
$$

where $E_{2 e c}$ is the slope of the second linear portion of the concrete stress-strain curve, and $D_{o}$ is the outer diameter of the CFFTs.

The above stress-strain models were adopted for the calculation of the interaction diagrams of FTRC specimens. The tensile stress carried by the concrete was neglected, and the actual longitudinal compressive strains at the extreme compression fibre of FRP tubes were used as the ultimate compressive strains. Fig. 13 compares the experimental and analytical interaction diagrams of specimens in Groups IT and ITG. It can be seen that the analytical results are in good agreement with experimental results. The predication results underestimated the bending moment capacities of FTRC specimens subjected to both eccentric loading and flexural loading conditions. However, the predicated load carrying capacities fit well with the experimental values of FTRC specimens.

For Specimens IT-F and ITG-F, the bending moment carried by each component (inner CFFTs and concrete cover) was investigated, as shown in Table 5. At the maximum load before cover spalling $P_{y}$, the bending moment carried by concrete cover $M_{y, \text { cover }}$ was 14.3 $\mathrm{kN} \cdot \mathrm{m}$ for Specimen ITG-F, which was $43 \%$ of the bending moment $M_{y}(33.1 \mathrm{kN} \cdot \mathrm{m})$. However, at the maximum load $P_{u}$, the bending moment carried by the concrete cover $M_{u, c o v e r}$ 
was reduced to $7.7 \mathrm{kN} \cdot \mathrm{m}$, which was only $20 \%$ of the bending moment $M_{u}$. Even though the bending moment carried by the concrete cover was significantly reduced with the increase of longitudinal compressive strains, the bending moment carried by the inner CFFTs $M_{u, C F F T s}$ was increased (from $18.7 \mathrm{kN} \cdot \mathrm{m}$ to $29.8 \mathrm{kN} \cdot \mathrm{m}$ for Specimen ITG-F). Moreover, the increase in the bending moment carried by inner CFFTs was higher than the decrease in the bending moment carried by concrete cover. Therefore, a higher bending moment capacity $M_{u}$ can be obtained for Specimens ITG-F after the spalling of concrete cover. In addition, the mid-span deflection of Specimen ITG-F was predicted by using the proposed analytical model. Firstly, the moment-curvature response was calculated. Afterwards, the mid-span deflection was calculated by using the moment-area method, as suggested in Mandal and Fam (2006). The ultimate mid-span deflection for Specimen ITG-F was calculated to be $17.2 \mathrm{~mm}$, which was close to the experimental value $(23.3 \mathrm{~mm})$. Therefore, the proposed model can also predict the mid-span deflection of FTRC specimens with reasonable accuracy.

\section{Conclusions}

In this study, experimental and analytical investigations were carried out to study the behavior of FRP tube reinforced concrete (FTRC) columns under different loading conditions. Based on these results, the following conclusions can be drawn:

1. The axial load carrying capacities of FTRC columns (Group IT, ITG, and PT) are higher than that of Group REF columns under both concentric and eccentric loadings. The axial load carrying capacity of FTRC columns is significantly reduced with the increase of eccentricity. PT, and REF columns. 

both concentric and eccentric loading conditions. The ductility of FTRC columns increases with the increase of load eccentricity.

3. Among the four beam specimens REF-F, IT-F, ITG-F, and PT-F, Specimen REF-F has the highest load carrying capacity, followed by Specimens ITG-F, IT-F, and PT-F. The highest mid-span deflection is obtained by Specimen REF-F, followed by Specimens PT-F, ITG-F, and IT-F.

4. Both experimental and analytical interaction diagrams of FTRC specimens are constructed. The analytical investigation can predict the load carrying capacity and bending moment capacity of FTRC specimens with good accuracy. It has been observed that a higher bending moment capacity may be obtained for FTRC specimens even after the spalling of concrete cover due to the increased bending moment carried by the inner CFFTs of FTRC specimens.

5. The above conclusions are based on the experimental investigations on 16 concrete specimens. Hence, more experimental investigations need to be conducted to fully validate the observed behavior of FTRC specimens under different loading conditions. Moreover, the performance of FTRC specimens under harsh environments (e.g., aggressive freeze-thaw cycles in cold regions and extreme temperature conditions) need to be extensively 474 investigated.

\section{Acknowledgments}

477 The authors would like to acknowledge the senior technical officer Mr. Ritchie Mclean, who 478 constructed the four-point loading system used in this study. The contributions from Mr. Alan 479 Grant and Mr. Fernando Escribano for their help in carrying out the experiments are also 
acknowledged. Furthermore, the first author acknowledges the China Scholarship Council and the University of Wollongong for supporting his $\mathrm{PhD}$ scholarship.

\section{References}

Australian Standard (AS). (2007). "Metallic materials-Tensile testing at ambient Australian Standard (AS). (2009). "Concrete structures.” 3600:2009, Sydney, NSW, Australia.

Bank, L. (2013). "Progressive failure and ductility of FRP composites for construction: review." Journal of Composites for Construction, 17(3), 406-419.

China Planning Press. (2010). Technical code for infrastructure application of FRP composites, GB-50608, China.

Cree, D., Chowdhury, E. U., Green, M. F., Bisby, L. A., and Bénichou, N. (2012). "Performance in fire of FRP-strengthened and insulated reinforced concrete columns." Fire Safety Journal, 54, 86-95.

Cromwell, J. R., Harries, K. A., and Shahrooz, B. M. (2011). "Environmental durability of externally bonded FRP materials intended for repair of concrete structures." Construction and Building Materials, 25(5), 2528-2539.

Cui, C., and Sheikh, S. (2010). "Experimental study of normal- and high-strength concrete confined with fiber-reinforced polymers." Journal of Composites for Construction, 14(5), 553-561.

Exel Composites Australia. (2015). 991 Mountain Highway, Boronia, Melbourne, VIC Australia. <http://www.exelcomposites.com.au/> (January, 2015).

Fam, A. Z., and Rizkalla, S. H. (2001). "Behavior of axially loaded concrete-filled circular fiber-reinforced polymer tubes.” ACI Structural Journal, 98 (3), 280-289.

Fam, A. Z., and Rizkalla, S. H. (2002). "Flexural behavior of concrete-filled fiber-reinforced polymer circular tubes.” Journal of Composites for Construction, 6 (2), 123-132.

Fam, A. Z., Flisak, B., and Rizkalla, S. (2003). "Experimental and analytical modeling of concrete-filled fiber-reinforced polymer tubes subjected to combined bending and axial loads." ACI Structural Journal, 100 (4), 499-509.

GB/T (2005). "Test method for longitudinal compressive properties of fiber-reinforced thermosetting plastic pipe." GB/T 5350-2005,China. 
Green, M. F., Bisby, L. A., Fam, A. Z., and Kodur, V. K. R. (2006). "FRP confined concrete columns: Behavior under extreme conditions." Cement and Concrete Composites, 28(10), 928-937.

Hadi, M. N. S., and Schmidt, L. (2002). "Use of helices in reinforced concrete beams." ACI Structural Journal, 99 (2), 191-198.

Hadi, M. N. S., Wang, W., and Sheikh, M. N. (2015). "Axial compressive behavior of GFRP tube reinforced concrete columns." Construction and Building Materials, 81, 198-207.

Hadi, M. N. S., and Zhao, H. (2011). "Experimental study of high-strength concrete columns confined with different types of mesh under eccentric and concentric loads." Journal of Materials in Civil Engineering, 23(6), 823-832.

Heo, Y.-S., Sanjayan, J. G., Han, C.-G., and Han, M.-C. (2011). "Construction application of Fibre/Mesh method for protecting concrete columns in fire." Construction and Building Materials, 25(6), 2928-2938.

Jau, W.-C., and Huang, K.-L. (2008). "A study of reinforced concrete corner columns after fire." Cement and Concrete Composites, 30(7), 622-638.

Ji, G., Li, G., Li, X., Pang, S., and Jones, R. (2008). "Experimental study of FRP tube encased concrete cylinders exposed to fire." Composite Structures, 85 (2), 149-154.

Karbhari, V., Chin, J., Hunston, D., Benmokrane, B., Juska, T., Morgan, R., Lesko, J., Sorathia, U., and Reynaud, D. (2003). "Durability gap analysis for fiber-reinforced polymer composites in civil infrastructure.” Journal of Composites for Construction, 7(3), 238-247.

Maccaferri Australia Pty Ltd. (2015). 22 Powers Road, Seven Hills, Sydney, NSW, Australia. $<$ http://www.maccaferri.com.au/> (Accessed on February 2015).

Mandal, S., and Fam, A. (2006). "Modeling of prestressed concrete-filled circular composite tubes subjected to bending and axial loads." Journal of Structural Engineering, 132(3), 449459.

Mander, J. B., Priestley, M. J. N., and Park, R. (1988). "Theoretical stress-strain model for confined concrete.” Journal of Structural Engineering 114(8), 1804-1826.

Mirmiran, A., Shahawy, M., Samaan, M., El Echary, H., Mastrapa, J. C., and Pico, O. (1998). "Effect of column parameters on FRP-confined concrete." Journal of Composites for Construction, 2(4), 175-185.

Mohamed, H. M., and Masmoudi, R. (2010). "Flexural strength and behavior of steel and FRP-reinforced concrete-filled FRP tube beams." Engineering Structures, 32(11), 3789-3800.

Ozbakkaloglu, T. (2013). "Compressive behavior of concrete-filled FRP tube columns: Assessment of critical column parameters.” Engineering Structures, 51, 188-199.

Park, H., Lee, H., Choi, I., Kim, S., and Park, S. (2015). "Concrete-filled steel tube columns encased with thin precast concrete." Journal of Structural Engineering, 04015056. 
575 Pessiki, S., and Pieroni, A. (1997). "Axial load behavior of large-scale spirally-reinforced high-strength concrete columns.” ACI Structural Journal, 94(3), 304-314.

Pham, T. M., Doan, L. V., and Hadi, M. N. S. (2013). "Strengthening square reinforced concrete columns by circularisation and FRP confinement." Construction and Building Materials, 49, 490-499.

Popovics, S. (1973). "A numerical approach to the complete stress-strain curve of concrete." Cement and Concrete Research, 3(5), 583-599.

Rethnasamy, C., Rajagopal, T., and Muthuraj, H. (2013). "Bending behavior, deformability and strength analysis of Prefabricated Cage Reinforced Composite beams." Construction and Building Materials, 38, 482-490.

Sezen, H., and Shamsai, M. (2008). "High-strength concrete columns reinforced with prefabricated cage system." Journal of Structural Engineering, 134(5), 750-757.

Teng, J. G., Jiang, T., Lam, L., and Luo, Y. Z. (2009). "Refinement of a design-oriented stress-strain model for FRP-confined concrete." Journal of Composites for Construction, 13(4), 269-278.

Wang, W., Sheikh, M. N., and Hadi, M. N. S. (2015a). "Axial compressive behaviour of concrete confined with polymer grid." Materials and Structures/Materiaux et Constructions, $1-16$.

Wang, W., Sheikh, M. N., and Hadi, M. N. S. (2015b). "Behaviour of perforated GFRP tubes under axial compression.” Thin-Walled Structures, 95, 88-100.

Wu, Y.-F., and Jiang, C. (2013). "Effect of load eccentricity on the stress-strain relationship of FRP-confined concrete columns.” Composite Structures, 98, 228-241.

Yazici, V. and Hadi, M. N. S. (2009). "Axial load-bending moment diagrams of carbon FRP wrapped hollow core reinforced concrete columns." Journal of Composites for Construction, 13(4), 262-268.

Yu, B., and Kodur, V. K. R. (2013). "Factors governing the fire response of concrete beams reinforced with FRP rebars." Composite Structures, 100, 257-269.

Yu, T., Wong, Y. L., and Teng, J. G. (2010). "Behavior of hybrid FRP-concrete-steel doubleskin tubular columns subjected to eccentric compression." Advances in Structural Engineering, 13(5), 961-974. 
624 List of Tables

625 Table 1. Test Matrix

626 Table 2. Mechanical Properties of GFRP Tubes

627 Table 3. Results of Specimens Tested under Concentric and Eccentric Loadings

628 Table 4. Results of Specimens Tested under Four-Point Loading

629 Table 5. Analytical Results of Specimens IT-F and ITG-F 
631 Fig. 1. Details of test specimens

632 Fig. 2. Eccentric loading system (all units are in $\mathrm{mm}$ )

633 Fig. 3. Four-point loading system (all units are in $\mathrm{mm}$ )

634 Fig. 4. Failure modes of Specimens REF-0, IT-0, ITG-0, and PT-0

635 Fig. 5. Axial load-axial deformation behavior of specimens under concentric load

636 Fig. 6. Failure modes of Specimens REF-25, IT-25, ITG-25, and PT-25

637 Fig. 7. Axial load-axial deformation and axial load-lateral deflection behavior of specimens 638 under eccentric load (eccentricity, e=25 mm)

639 Fig. 8. Axial load-axial deformation and axial load-lateral deflection behavior of specimens 640 under eccentric load (eccentricity, e=50 mm)

641 Fig. 9. Failure modes of beam specimens

642 Fig. 10. Load-midspan deflection behavior of specimens under four-point loading

643 Fig. 11. Experimental interaction $(P-M)$ diagrams

644 Fig. 12. Strain and stress distribution of FTRC columns

645 Fig. 13. Comparison between analytical and experimental interaction $(P-M)$ diagrams

646

647

648

649 


\begin{tabular}{|c|c|c|c|}
\hline Specimen & Internal Reinforcement & Cover Confinement & Test Modes \\
\hline REF-0 & 6N12 and R10@50 mm & -- & Concentric \\
\hline REF-25 & 6N12 and R10@50mm & -- & Eccentric, e $=25 \mathrm{~mm}$ \\
\hline REF-50 & 6N12 and R10@50 mm & -- & Eccentric, $\mathrm{e}=50 \mathrm{~mm}$ \\
\hline REF-F & 6N12 and R10@50mm & -- & Flexural \\
\hline IT & Intact GFRP tube & -- & Concentric \\
\hline IT-25 & Intact GFRP tube & -- & Eccentric, $\mathrm{e}=25 \mathrm{~mm}$ \\
\hline IT-50 & Intact GFRP tube & -- & Eccentric, $\mathrm{e}=50 \mathrm{~mm}$ \\
\hline IT-F & Intact GFRP tube & -- & Flexural \\
\hline ITG-0 & Intact GFRP tube & 2 layers of polymer grids & Concentric \\
\hline ITG-25 & Intact GFRP tube & 2 layers of polymer grids & Eccentric, $\mathrm{e}=25 \mathrm{~mm}$ \\
\hline ITG-50 & Intact GFRP tube & 2 layers of polymer grids & Eccentric, $\mathrm{e}=50 \mathrm{~mm}$ \\
\hline ITG-F & Intact GFRP tube & 2 layers of polymer grids & Flexural \\
\hline PT-0 & Perforated GFRP tube & -- & Concentric \\
\hline PT-25 & Perforated GFRP tube & -- & Eccentric, e $=25 \mathrm{~mm}$ \\
\hline PT-50 & Perforated GFRP tube & -- & Eccentric, $\mathrm{e}=50 \mathrm{~mm}$ \\
\hline PT-F & Perforated GFRP tube & -- & Flexural \\
\hline
\end{tabular}


Table 2. Mechanical Properties of GFRP Tubes (Exel Composites Australia 2015)

\begin{tabular}{cccccccc}
\hline Ultimate Tensile Strength (MPa) & Ultimate Compressive Strength (MPa) & & $\begin{array}{c}\text { Shear Strength } \\
(\mathrm{MPa})\end{array}$ & $\begin{array}{c}\text { Modulus of Elasticity } \\
(\mathrm{GPa})\end{array}$ & Longitudinal & Transverse \\
\cline { 1 - 6 } & Transverse & Longitudinal & Transverse & & 30 & 10 \\
\hline 450 & 50 & 450 & 80 & 25 & 30 \\
\hline
\end{tabular}


655 Table 3. Results of Specimens Tested under Concentric and Eccentric Loadings

\begin{tabular}{|c|c|c|c|c|c|c|}
\hline Specimen & $\begin{array}{l}\text { Yield load } \\
\quad(\mathrm{kN})\end{array}$ & $\begin{array}{l}\text { Axial deformation } \\
\text { at yield load (mm) }\end{array}$ & $\begin{array}{l}\text { Ultimate load } \\
\qquad(\mathrm{kN})\end{array}$ & $\begin{array}{l}\text { Axial deformation } \\
\text { at ultimate load }(\mathrm{mm})\end{array}$ & $\begin{array}{l}\text { Lateral deflection } \\
\text { at ultimate load (mm) }\end{array}$ & Ductility \\
\hline REF-0 & 1275 & 1.82 & 1486 & 2.83 & -- & 1.87 \\
\hline IT-0 & 1405 & 2.05 & 1850 & 6.21 & -- & 3.03 \\
\hline ITG-0 & 1271 & 1.70 & 1849 & 6.04 & -- & 3.55 \\
\hline PT-0 & 1052 & 1.55 & 1415 & 5.26 & -- & 3.39 \\
\hline REF-25 & 899 & 1.94 & 986 & 2.40 & 1.38 & 1.44 \\
\hline IT-25 & 1038 & 2.19 & 1474 & 6.70 & 5.14 & 3.06 \\
\hline ITG-25 & 1054 & 2.09 & 1558 & 7.06 & 4.95 & 3.38 \\
\hline PT-25 & 1002 & 2.24 & 1400 & 6.10 & 4.19 & 2.72 \\
\hline REF-50 & 653 & 2.02 & 696 & 2.45 & 2.32 & 1.47 \\
\hline IT-50 & 675 & 1.82 & 1038 & 9.36 & 7.31 & 5.14 \\
\hline ITG-50 & 680 & 2.09 & 1046 & 8.84 & 6.71 & 4.23 \\
\hline PT-50 & 686 & 1.92 & 915 & 9.64 & 5.69 & 2.96 \\
\hline
\end{tabular}


Table 4. Results of Specimens Tested under Four-Point Loading

\begin{tabular}{lcccccc}
\hline Specimen & $\begin{array}{c}\text { Maximum load before } \\
\text { cover spalling } P_{y}(\mathrm{kN})\end{array}$ & $\begin{array}{c}\text { Corresponding mid- } \\
\text { span deflection } \\
\delta_{y}(\mathrm{~mm})\end{array}$ & $\begin{array}{c}\text { Bending moment } \\
M_{y}(\mathrm{kN} \cdot \mathrm{m})\end{array}$ & $\begin{array}{c}\text { Maximum load } \\
P_{u}(\mathrm{kN})\end{array}$ & $\begin{array}{c}\text { Mid-span deflection at } \\
\text { Maximum load } \delta_{u}(\mathrm{~mm})\end{array}$ & $\begin{array}{c}\text { Bending moment } \\
M_{u}(\mathrm{kN} \cdot \mathrm{m})\end{array}$ \\
\hline REF-F & 322 & 8.48 & 37.8 & 369 & 25.56 & 43.39 \\
IT-F & 337 & 11.39 & 39.6 & 337 & 23.33 & 39.6 \\
ITG-F & 340 & 8.92 & 40.0 & 348 & 8.86 & 36.9 \\
PT-F & 311 & 8.86 & 36.5 & 311 & \\
\hline
\end{tabular}

658 
Table 5. Analytical Results of Specimens IT-F and ITG-F

\begin{tabular}{lcccccc}
\hline Specimen & $M_{y}(\mathrm{kN} \cdot \mathrm{m})$ & $M_{y, \text { CFFTs }}(\mathrm{kN} \cdot \mathrm{m})$ & $M_{y, \text { cover }}(\mathrm{kN} \cdot \mathrm{m})$ & $M_{u}(\mathrm{kN} \cdot \mathrm{m})$ & $M_{u, \text { CFFTs }}(\mathrm{kN} \cdot \mathrm{m})$ & $M_{u, \text { cover }}(\mathrm{kN} \cdot \mathrm{m})$ \\
\hline IT-F & 33.9 & 20.0 & 13.9 & 33.9 & 20.0 & 13.9 \\
ITG-F & 33.1 & 18.7 & 14.3 & 37.5 & 29.8 & 7.7 \\
\hline
\end{tabular}

662 Note: $M_{y}$ indicates the bending moment at the maximum load before cover spalling $P_{y} ; M_{y, C F F T s}$ and $M_{y, \text { cover }}$ indicates the bending moment 663 carried by the inner CFFTs and concrete cover at the maximum load before cover spalling $P_{y}$, respectively; $M_{u}$ indicates the bending moment at 664 the maximum load; $M_{u, \text { CFFTs }}$ and $M_{u, \text { cover }}$ indicates the bending moment carried by the inner CFFTs and concrete cover at the maximum load $P_{u}$, 665 respectively. 


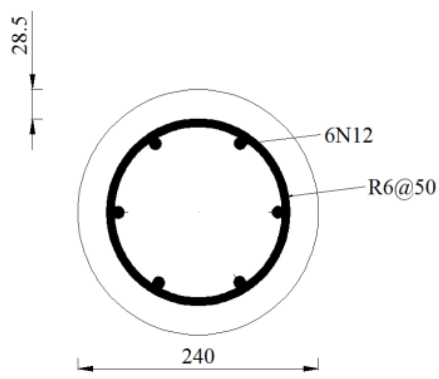

(a) Group REF

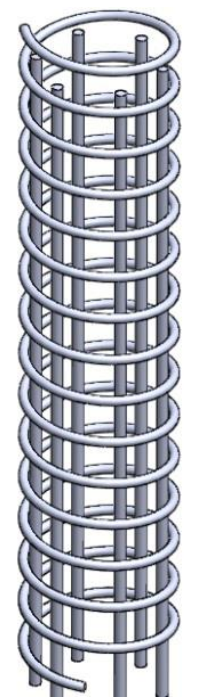

(d) Group REF

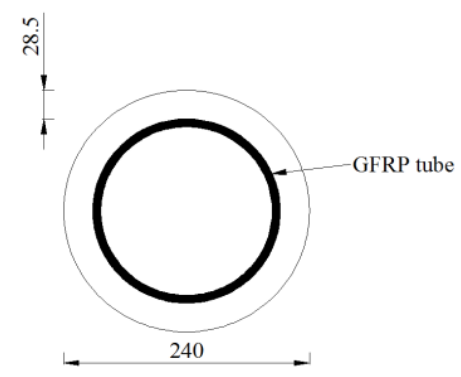

(b) Group IT, PT

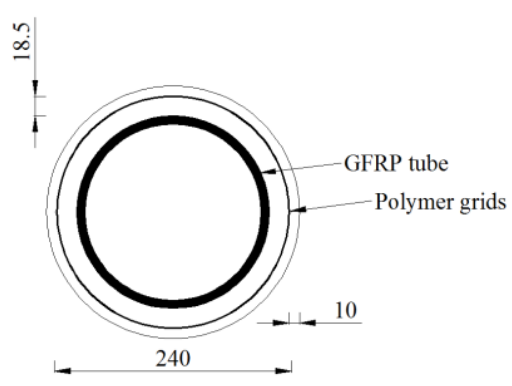

(c) Group ITG

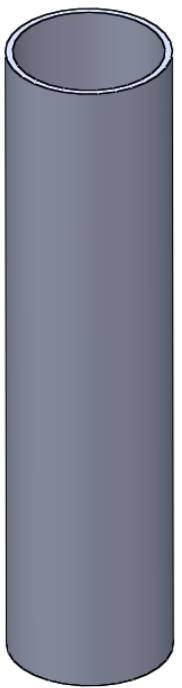

(e) Group IT

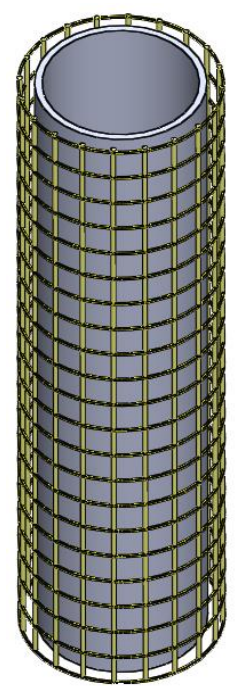

(f) Group ITG

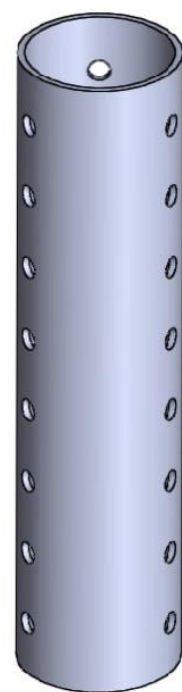

(g) Group PT

Fig. 1. Details of test specimens 


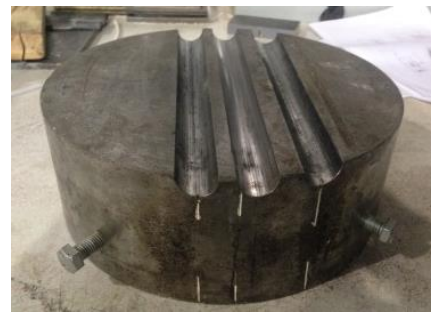

(a) adaptor plate

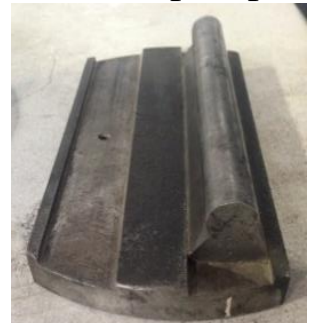

(b) steel plate with ball joint

Fig. 2. Eccentric loading system (all units are in mm)

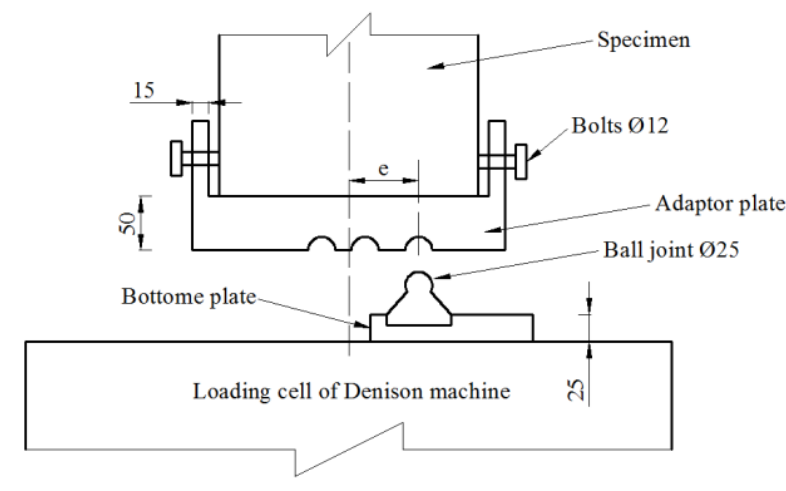

(c) loading system 


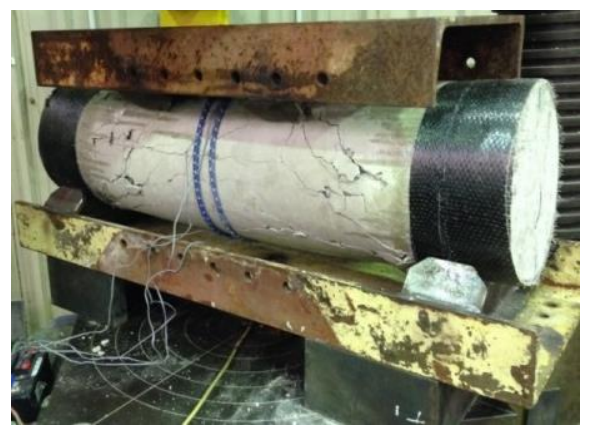

(a) Four-point loading apparatus

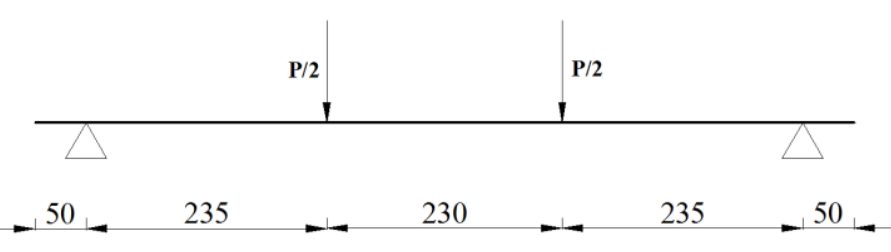

(b) Demensions of test set-up

Fig. 3. Four-point loading system (all units are in $\mathrm{mm}$ ) 


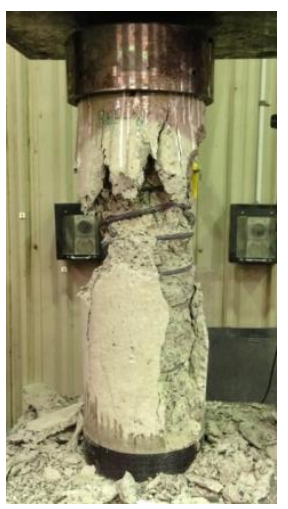

(a) REF-0

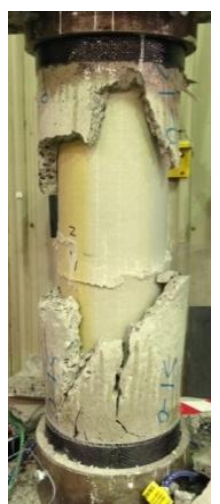

(b) IT-0

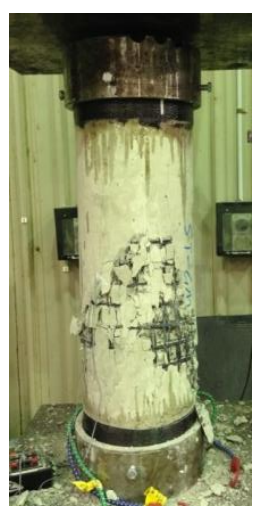

(c) ITG-0

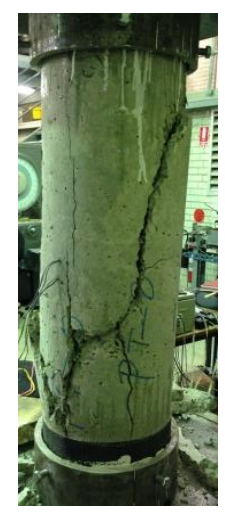

(d) PT-0

Fig. 4. Failure modes of Specimens REF-0, IT-0, ITG-0, and PT-0 


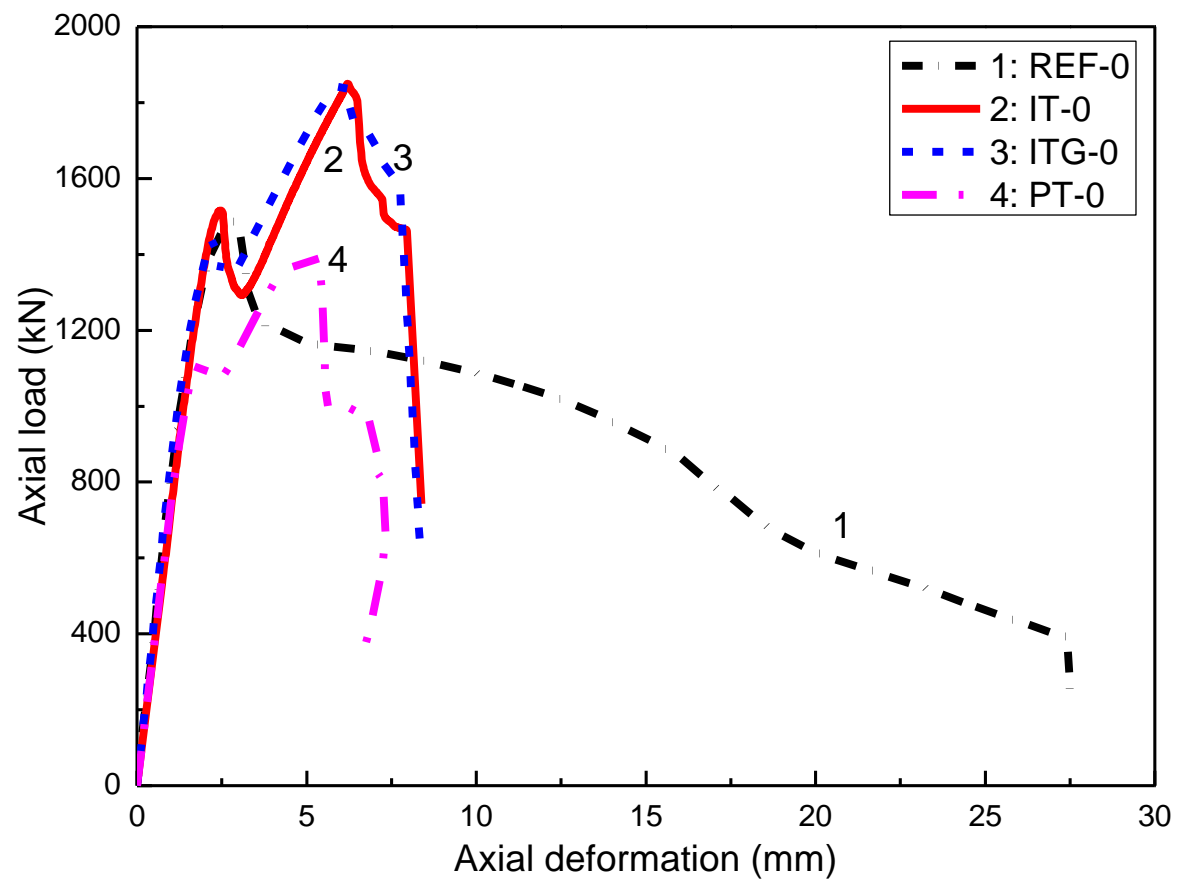

Fig. 5. Axial load-axial deformation behavior of specimens under concentric load 


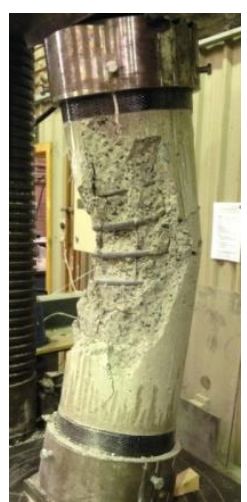

(a) REF-25

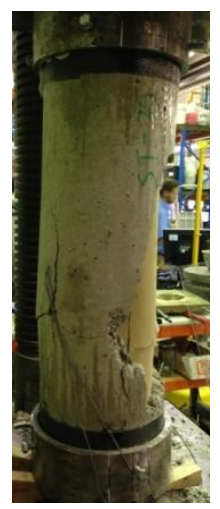

(b) IT-25

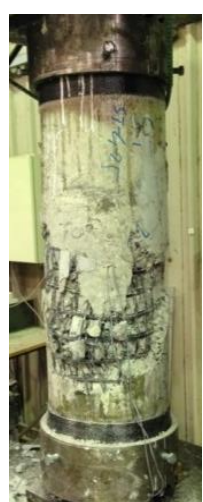

(c) ITG-25

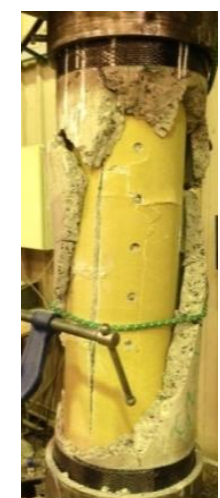

(d) PT-25

Fig. 6. Failure modes of Specimens REF-25, IT-25, ITG-25, and PT-25 


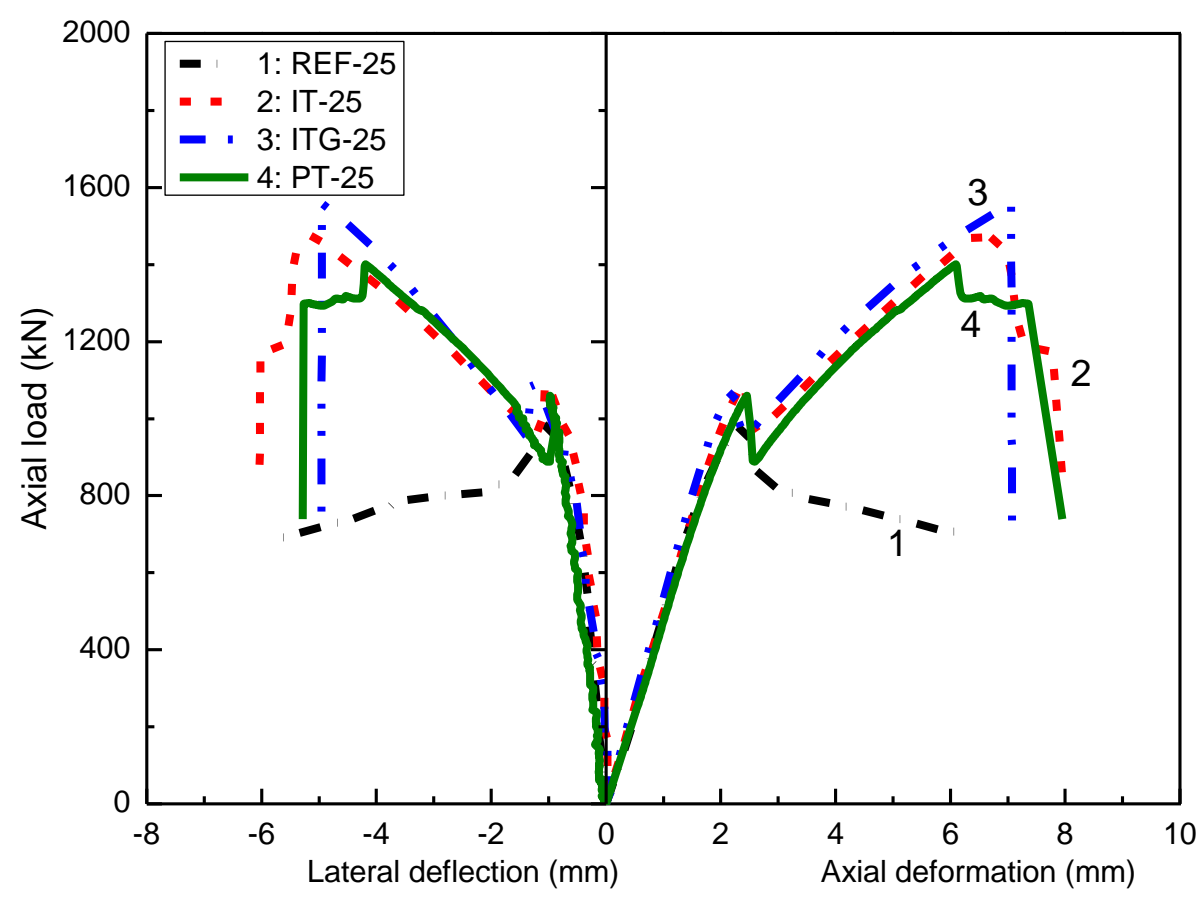

Fig. 7. Axial load-axial deformation and axial load-lateral deflection behavior of specimens under eccentric load (eccentricity, e=25 mm) 


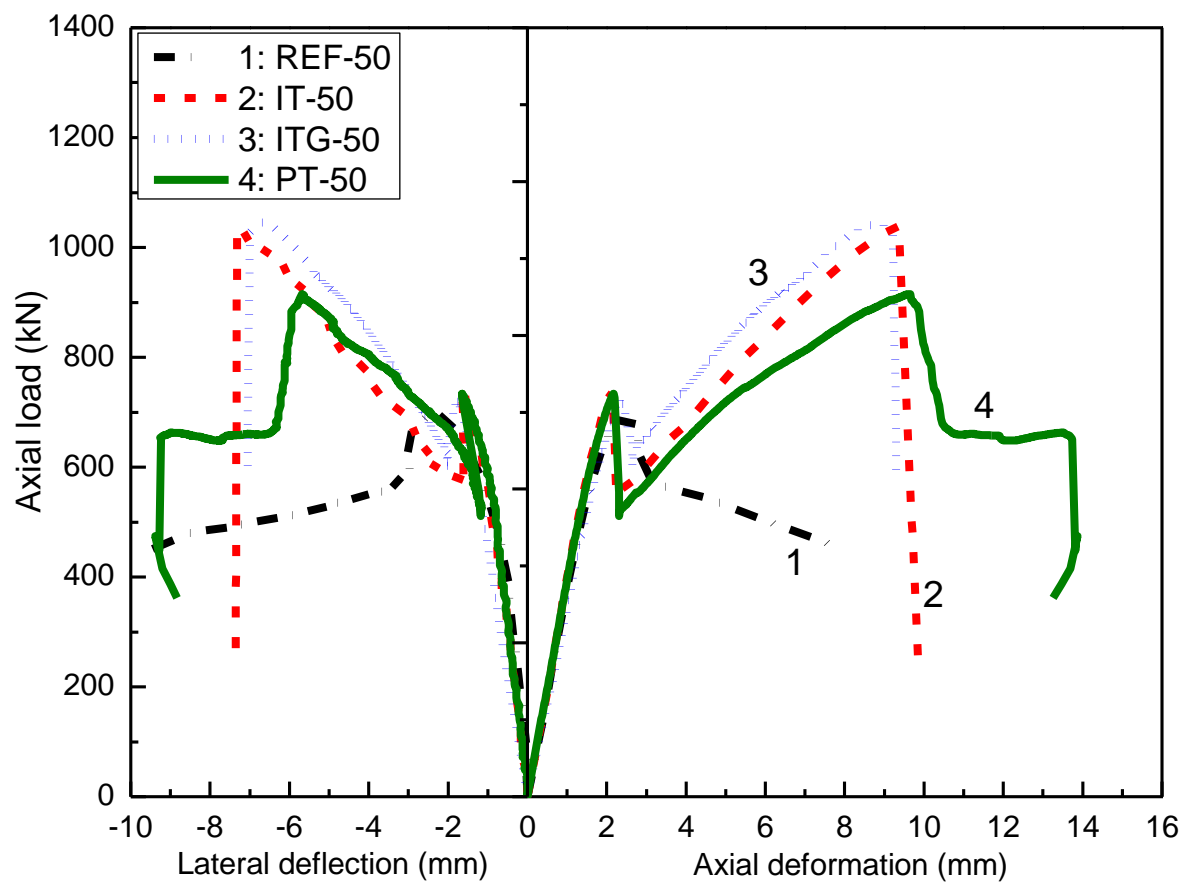

Fig. 8. Axial load-axial deformation and axial load-lateral deflection behavior of specimens under eccentric load (eccentricity, e=50 mm) 


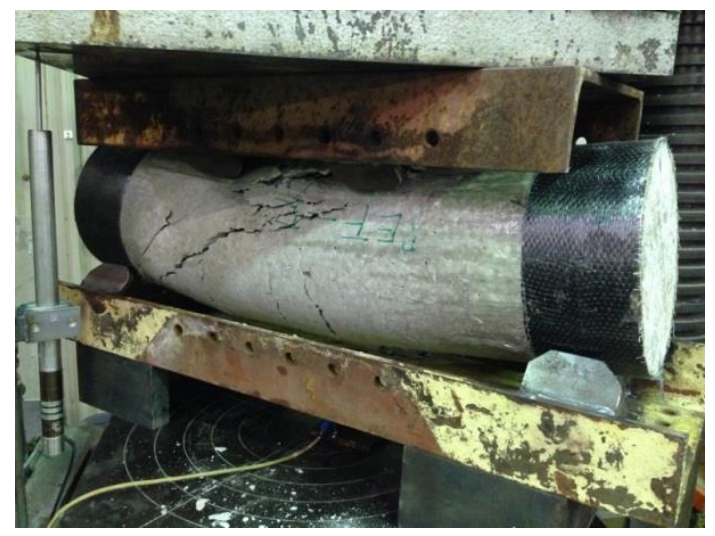

(a) REF-F

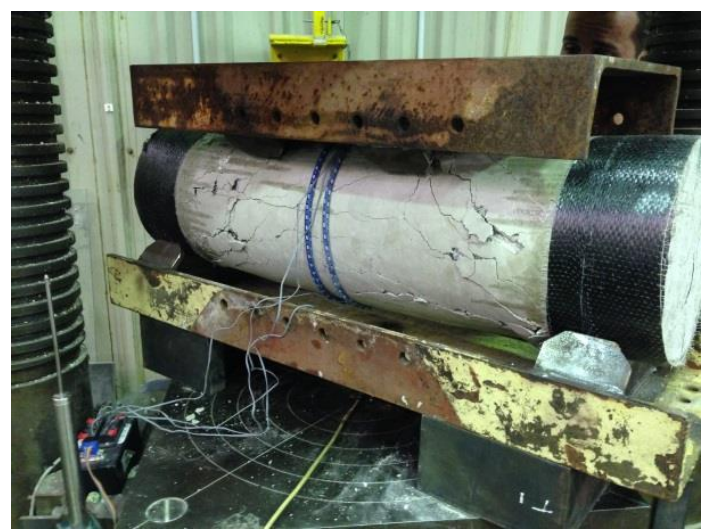

(c) ITG-F

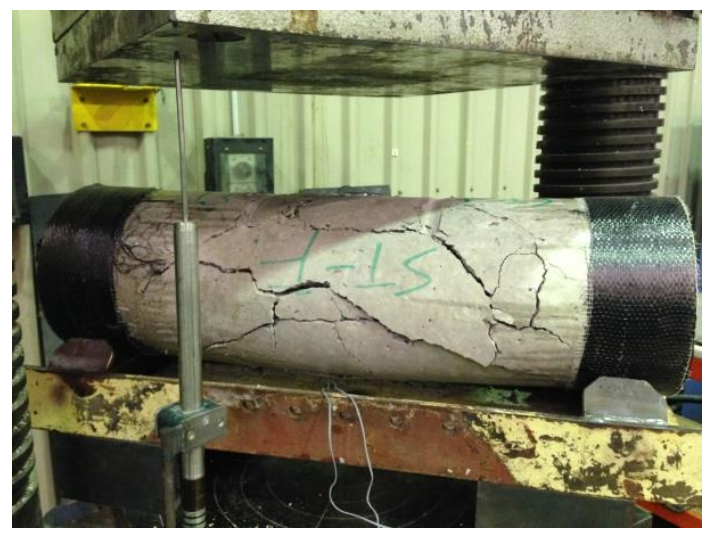

(b) IT-F

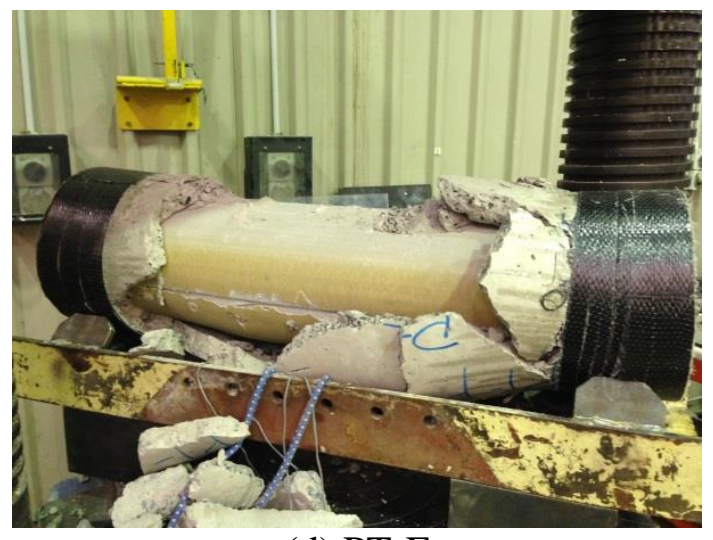

(d) PT-F

Fig. 9. Failure modes of beam specimens 


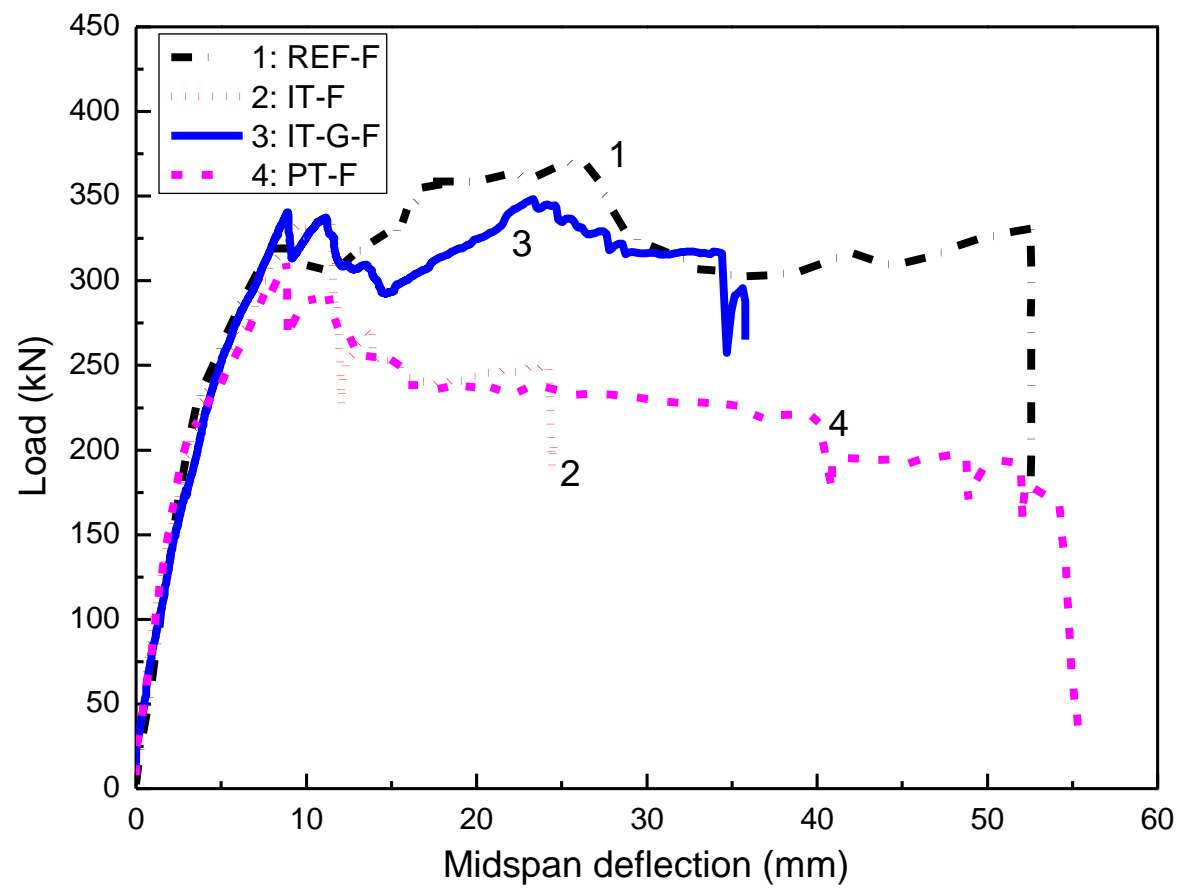

Fig. 10. Load-midspan deflection behavior of specimens under four-point loading 


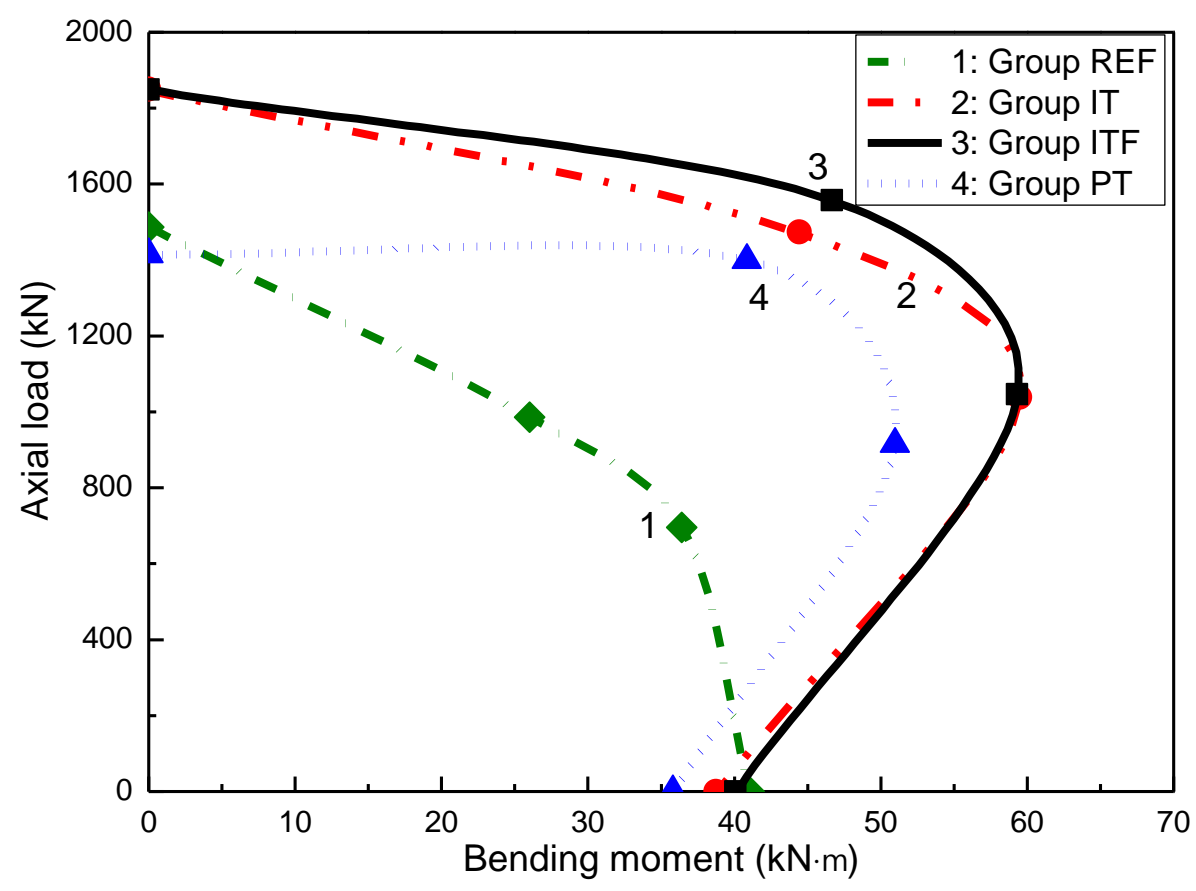

Fig. 11. Experimental interaction $(P-M)$ diagram 


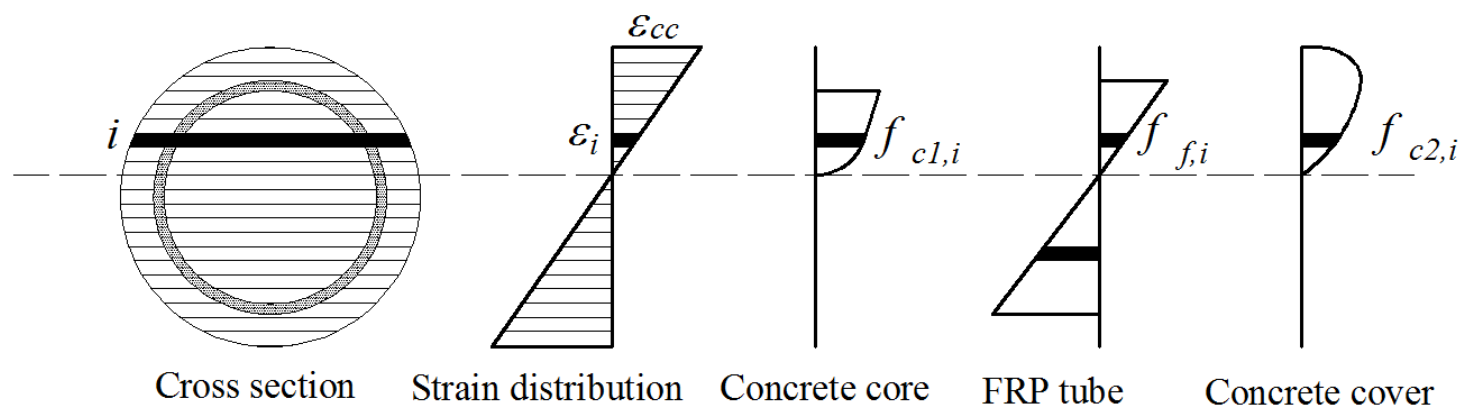

Fig. 12. Strain and stress distribution of FTRC columns 


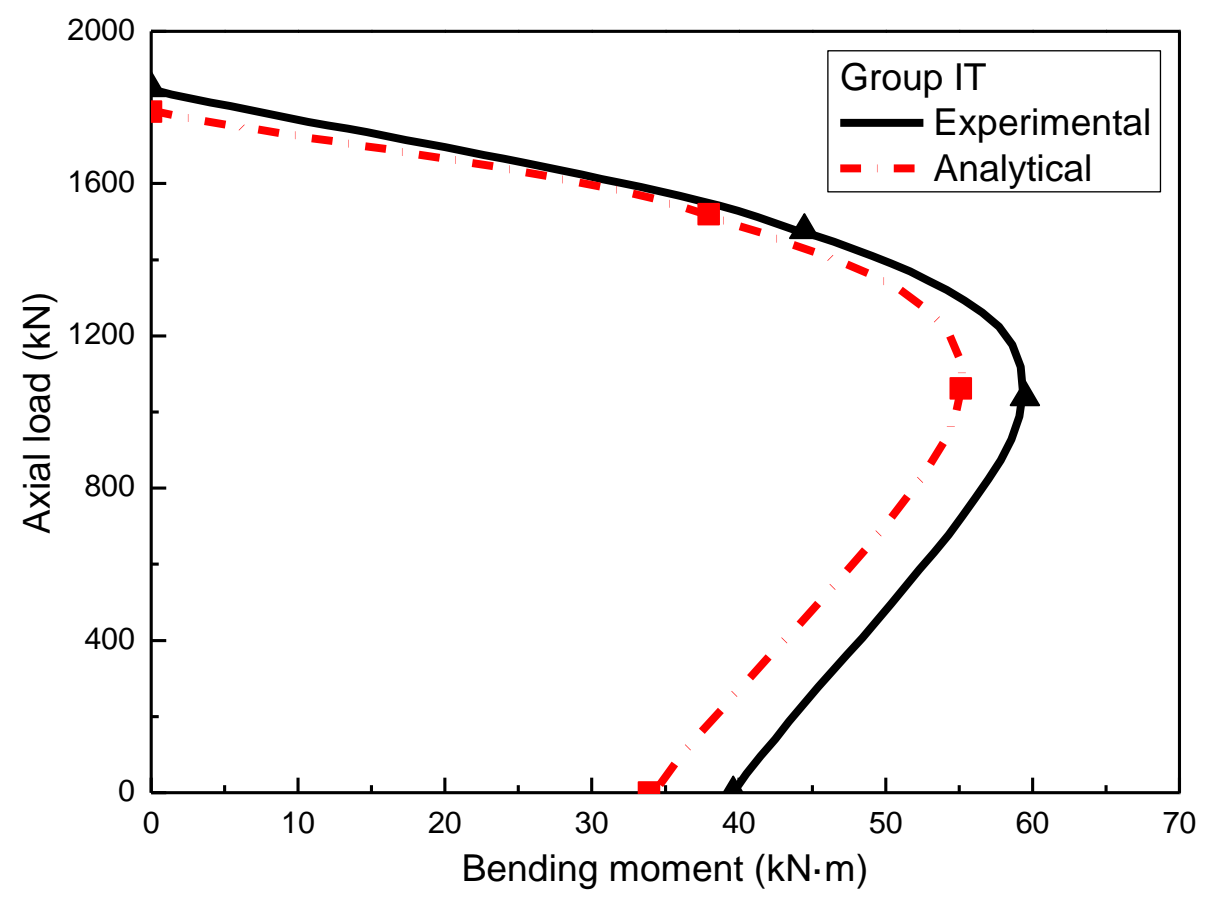

(a) $P-M$ diagrams of Group IT specimens

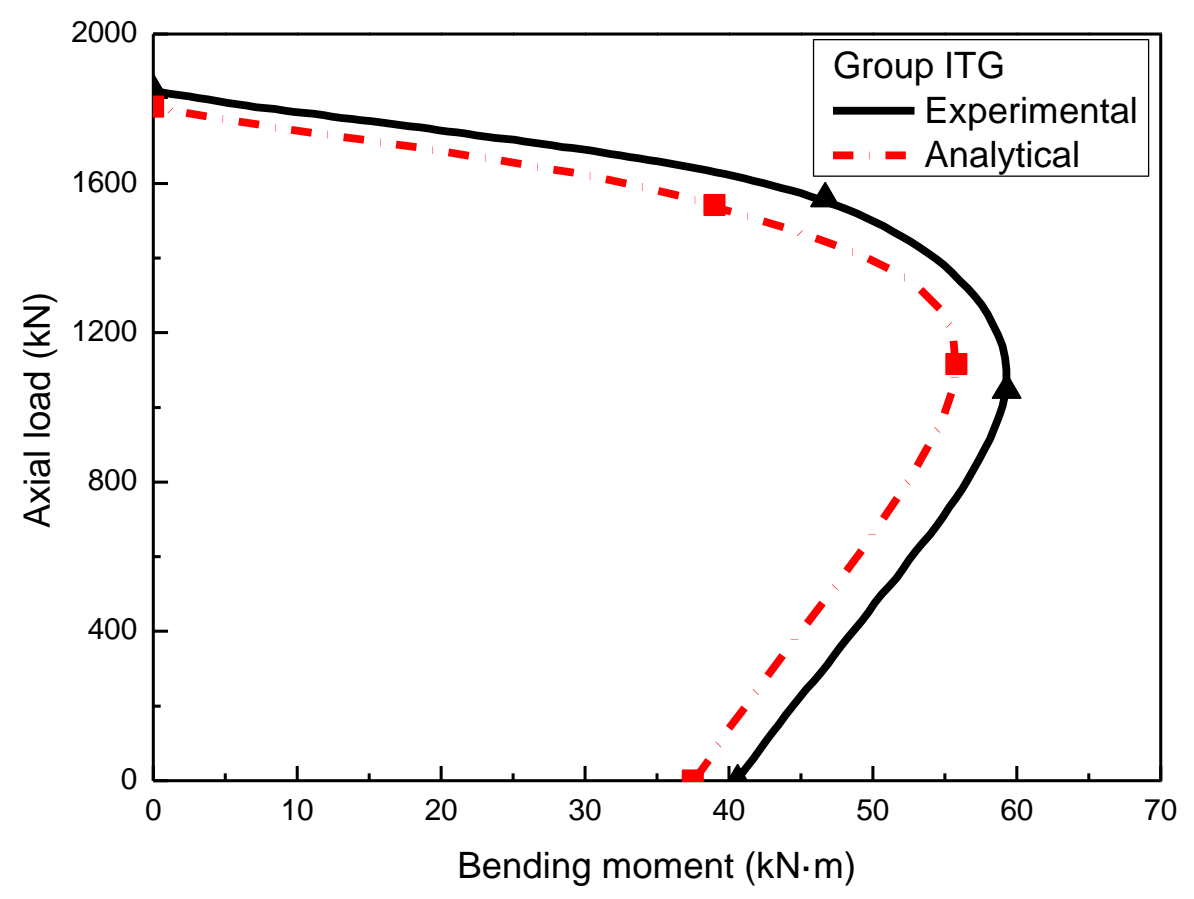

(b) $P-M$ diagrams of Group ITG specimens

Fig. 13. Comparison between analytical and experimental interaction $(P-M)$ diagrams 